\title{
Relationship dynamics: the protective effect of relationship satisfaction and dependency on parents' mental health after having a preterm baby
}

\section{BACKGROUND}

Having a premature infant who is hospitalized with the risk of death and potential health problems is a traumatic experience for many parents. The present study investigated the depression, anxiety, stress, and post-traumatic growth (PTG) experienced by couples after the premature birth of their babies in terms of their relationship dynamics.

\section{PARTICIPANTS AND PROCEDURE}

The study was conducted on 209 individuals - 159 mothers (76.1\%) and 50 fathers $(23.9 \%)$ - who had premature babies born at or before 32 weeks of gestation. The participants completed the Relationship Assessment Scale, Emotional Dependency Scale, Post-Traumatic Growth Inventory, the Depression, Anxiety, and Stress Scale, and a sociodemographic form. For interpretation of the data, intervariable relationships were analyzed using the Pearson correlation coefficient, and the mediation models were analyzed by the regression-based bootstrapping technique using the PROCESS Macro.

\section{RESULTS}

The relationship satisfaction and emotional dependency experienced by parents had a positive correlation with PTG following preterm birth. Relationship satisfaction was associated with lower levels of depression, anxiety, and stress. Emotional dependency was correlated with lower levels of depression and stress but not anxiety. For the mediating variables, it was found that depression and anxiety had a full mediating role between relationship satisfaction and PTG but stress did not. It was determined that depression had a partial mediating role between emotional dependency and PTG but anxiety and stress did not.

\section{CONCLUSIONS}

The study findings revealed the importance of establishing family- and baby-centered neurodevelopmental neonatal intensive care units (NICUs). The results suggested that having healthcare professionals, primarily nurses and doctors, make observations about the relationship dynamics of parents during their stay at the NICU and guide parents to receive psychological support if they perceive weaknesses in the relationship - since such weaknesses predict possible risks of depression, anxiety and stress - would support the functionality of families. The findings are discussed, and future directions are suggested.

\section{KEY WORDS}

premature birth; post-traumatic growth; depression; relationship dynamics

ORGANIZATION - 1: El Bebek Gül Bebek Association, Istanbul, Turkey · 2: Fatih Sultan Mehmet Vakıf University, Istanbul, Turkey

AUthors' Contributions - A: Study design - B: Data collection - C: Statistical analysis - D: Data interpretation .

E: Manuscript preparation · F: Literature search · G: Funds collection

Corresponding Author - Çiğdem Yavuz Güler, Ph.D., Fatih Sultan Mehmet Vakıf University, Valide-i Atik Mah. Eski Toptaşı Cad. 91, Üsküdar, Istanbul, Turkey, e-mail: cyavuzguler@fsm.edu.tr

TO CITE THIS ARTICLE - Okay, İ., \& Yavuz Güler, Ç. (2021). Relationship dynamics: the protective effect of relationship satisfaction and dependency on parents' mental health after having a preterm baby. Health Psychology Report, 9(4),

372-387. https://doi.org/10.5114/hpr.2021.108307

RECEIVED 10.02.2021 · REVIEWED 08.05.2021 · ACCEPTED 08.07.2021 · PUBLISHED 28.08.2021 


\section{BACKGROUND}

\section{PARENTING A PREMATURE BABY}

The duration of a normal pregnancy is expected to be anywhere from 37 to 40 weeks of gestation, and the World Health Organization defines babies born before 37 weeks as preterm. More than 1 in 10 babies in the world, adding up to approximately 15 million babies a year, are born preterm, and their families are affected (Howson et al., 2013). Moreover, as Blencowe et al. (2012) reported, over 1 million babies die due to complications caused by preterm birth.

Preterm infants need to be cared for in a neonatal intensive care unit (NICU), with the duration determined by the babies' condition. The more preterm and/or low weight an infant is at birth, the longer the infant needs to spend in the NICU, which also poses increased health risks. Being preterm can cause many lifelong problems for an infant from birth or in the NICU. Serious health problems and physical or mental barriers that may occur can impose heavy burdens on both the baby and the family that make life harder. In preterm birth, for every week a baby is born before the 38th gestational week, the risk of morbidity doubles (Shapiro-Mendoza et al., 2008). Whereas infants born at 24 weeks have a $50 \%$ chance of survival in high-income countries, the same rate applies only to those born at 34 weeks or older in low- and middle-income countries (Blencowe et al., 2012).

Under the difficult circumstances they face, parents who have preterm babies are subject to many stressors. The addition of a baby to the family is usually a happy event for families. However, in some circumstances, such as preterm birth or a birth with complications, it manifests as a traumatic event that poses a major stressor for the family and has the potential of affecting family dynamics. Ideally, birth is a magical experience of the mother uniting with the baby after months of anticipation during pregnancy; however, when a child is premature, the mother and baby must often be separated immediately after birth to administer neonatal care to the baby. Thus, the birth experience becomes traumatic, regardless of whether the threat of preterm birth was previously known to the parents (Affleck \& Tennen, 1991).

The second stressful period for parents of preterm infants starts immediately after the baby is discharged and taken home. Goldberg (1978) noted that the postdischarge care of preterm infants is much more difficult than that of term infants; preterm infants need to go to the hospital more often because of allergies, ear infections, and other health-related causes. Compared with parents of term infants, parents of preterm infants have to wait longer to see positive indicators of growth and development, such as laughing, motor development, and uninterrupted sleep. Thus, their stress persists for a long time, even after discharge (Goldberg, 1978). The first year of life of preterm infants is more difficult than it is for term infants, and parents must cope with greater physical, emotional, and financial burdens (Okumus, 2012).

Miles and Holditch-Davis (1997) suggested that parents of infants hospitalized in the NICU - especially mothers - have intense emotional responses. A synthesis of the findings from the descriptive studies reports that anxiety, helplessness and loss of control, and fear, as well as guilt and shame, depression and sadness, and a sense of failure and disappointment are the most typical feelings parents experience. Although studies indicate that extreme anxiety of parents decreases over time, parents still have worries and related anxiety when the infant is discharged home for care (Leahy-Warren et al., 2020; Treyvaud et al., 2019).

Schappin et al. (2013) reported that the stress levels of parents of preterm and term infants do not differ significantly. However, stress levels of parents vary depending on preterm infants' health characteristics, such as birth weight: the greater the birth weight, the smaller the difference. This may be because lower birth weight is associated with higher levels of infant morbidity and mortality (ShapiroMendoza et al., 2008).

Treyvaud et al. (2019) stated that preterm birth and admission to the NICU is a distressing and potentially traumatic experience for the parents. Their study suggested that parents need individual psychological and psychosocial support, peer-to-peer support, and broader early intervention programs to maintain and develop their wellbeing, including mental health. Parents, especially mothers, show symptoms of trauma following the preterm birth of their infant. Some suffer from psychological trauma even for a longer period after hospital discharge (Jotzo \& Poets, 2005). In their study, Leahy-Warren et al. (2020) observed that mothers of preterm infants are at a $38 \%$ higher risk of postpartum depression within the first year after NICU discharge. Not surprisingly, the results of the study also show that having a high level of functional support is associated with a lower level of depressive symptoms.

\section{THE PSYCHOLOGICAL IMPACT OF PARENTING A PREMATURE BABY AND RELATIONSHIP DYNAMICS}

Partners' deepest needs for close human connections are addressed in a romantic relationship. Romantic relationships are the source of emotional dependency on the partner. Emotional dependency can be defined as a person's attachment to the partner in a relationship and the importance of the relationship with the partner compared with other alternatives
Premature birth and parent's relationship dynamics 
İlknur Okay, Çiğdem Yavuz Güler and things in life (Buunk, 1982, 1995). Kemer et al. (2016) found that emotional dependency is the major predictor of relationship satisfaction among Turkish partners. This may be an expected positive outcome, considering the importance of humans' fundamental needs, such as being loved, connection with others, and intimacy. Robinson and Blanton (1993) included 'interdependence' in intimacy, which they defined as one of the characteristics of enduring marriages. Studies show that dependency is related to greater adjustment (Cirhinlioğlu et al., 2017; Rusbult \& Verette, 1991; Rusbult et al., 1991), relationship satisfaction (Erol \& Orth, 2013; Rusbult et al., 1991) better self esteem (Erol \& Orth, 2013; Robinson \& Cameron, 2012) in couples. In their study with 466 married individuals, Cirhinlioğlu et al. (2017) found that emotional dependency leads to better adjustment between partners, more effective communication, and more effective problem solving in the relationship.

Relationship quality is multidimensional and can be described using multiple terms, including relationship satisfaction, commitment, intimacy, affection, and understanding (Farooqi, 2014). We think that Kelley and Thibaut's (1978) interdependence theory offers a noteworthy explanation for satisfaction, dependence, and commitment in dyadic relationships. They note that interaction between partners is the essence of all intimate relationships. The theory suggests that satisfaction level and degree of dependence are two important components of an ongoing relationship. The investment model asserts that the state of dependence relates to feelings of commitment, where the commitment level is a psychological state that reflects the overall experience of dependence on a relationship. Rusbult and Buunk (1993) argued that the commitment level reflects the effects of other dependence-enhancing variables, such as satisfaction, alternatives, and investments. Highly committed individuals need to connect to their partners, and the satisfaction level affects the commitment level. Thus, individuals' level of commitment directly affects their dependence on their partner and the decision to terminate or remain in the relationship (Rusbult \& Buunk, 1993).

Stress is the state of emotion felt when problems that people need to deal with challenge their physical and psychological health and exceed their skills and available resources. All situations that require adaptation can be regarded as potential stressors. Stressors are external requirements that cause emotional disturbance; their effects on the organism are defined as stress, and the actions that are used for managing the stress are called coping mechanisms (Butcher et al., 2013).

According to Lazarus and Cohen (1977), in the study of stress, researchers in various disciplines have observed that stress has three features, and each of these features has attracted significant research at- tention. First, the emotion and effects of stress have a major effect on satisfaction and morale. Second, stress affects individuals' adaptation skills, such as problem solving, social coherence, and somatic health. Finally, when such emotions as anxiety, fear, guilt, resentment, sadness, or anger arise as a result of stress, their presence reveals that significant psychological events are taking place between individuals and their environments. The factors that indicate the potential level of influence of a stressor are defined by its severity, whether it is ongoing, the timing, how closely it affects the person's life, and how predictable and controllable it is (Butcher et al., 2013).

Depression is a state of deep dejection in which the individual feels severe sadness and despondency. It is often accompanied by impairment of thought, speech, psychomotor and physiological functions, and stagnation. It is also a syndrome characterized by feelings and thoughts of worthlessness, weakness, powerlessness, and pessimism (Ozturk \& Ulusahin, 2016). Perinatal depression describes depression experienced during pregnancy and within the first year after birth. Predisposition to mental illness increases the most in the perinatal period, and there are various biological and psychosocial factors affecting it. Low socioeconomic status, history of depression in an immediate family member, problems with the partner, a high-risk pregnancy, and a history of previous postpartum depression are some risk factors for perinatal depression (Ozturk \& Aydin, 2017).

Postpartum depression affects around $10-15 \%$ of mothers and is one of the most important complications of giving birth (O’Hara \& Swain, 1996). Although family history is considered for depression, some stressful experiences also increase the risk of postpartum depression (Vigod et al., 2010). In Vigod et al.'s (2010) review study, four studies out of six showed that the frequency of depression of the mothers of preterm infants was significantly higher, especially in the first year after birth, compared with mothers of term infants. The study also showed that mothers of preterm infants have a 1.6-fold increased risk of depression within the first 8 weeks after birth.

A study from Australia reported that $40 \%$ of 62 mothers who gave birth to preterm infants between the 24th and 32nd gestational weeks showed symptoms of depression (Davis et al., 2003). The main source of these symptoms was revealed to be maternal stress. It is clear that factors such as being separated from their small babies, who are facing many health risks and are even at risk of death; not being the primary caregiver; and spending time with their babies for only a limited time increase mothers' stress.

Preterm birth and maternal or fetal health problems that lead to it are also sources of stress. Ideally, a new mother will be healthy, and this will have 
a positive impact on the couple's relationship. However, if the pregnancy or birth is problematic, the family coping mechanisms have a protective effect on relationship satisfaction (Didericksen et al., 2015). Mothers who give birth preterm are under more psychological stress than other mothers are. A study by Bener (2013) on 1,659 mothers found that the rate of postpartum depression was $17.3 \%$ among the mothers of term infants, while it was $29.4 \%$ among the mothers of preterm infants.

Anxiety is a complex confluence of unpleasant emotions and cognitions that are similar to fear but are vaguer and associated with a sense of apprehension (Barlow, 1988). In their study, Zelkowitz et al. (2007) reported that $50 \%$ of mothers whose preterm infants had been admitted to the NICU showed symptoms of severe anxiety and depression. Anxiety is more common among mothers who give birth to preterm babies because of their concerns for the future; for instance, such mothers tend to be concerned about whether the baby will survive or have any permanent health problems in a way that mothers of term infants are not. Bener (2013) reported that the rates of anxiety and depression among the mothers of term and preterm infants were $11.6 \%$ and $26.5 \%$, respectively (Bener, 2013).

Pace et al. (2016) carried out a study to compare the parents of 150 infants born at under 30 gestational weeks and 151 term infants born after 37 weeks. They reported that $50 \%$ of parents of preterm infants showed severe anxiety symptoms shortly after birth. Although a decrease in anxiety symptoms was observed around 12 weeks, it was noted that the rate did not fall below $22 \%$ for mothers or $25 \%$ for fathers. Even 6 months after birth, parents of preterm infants were at higher risk of depression and anxiety compared with parents of term infants. Although it was not one of the goals of the study to compare the levels of depression and anxiety of mothers and fathers, the symptoms were found to be similar in both parents. This result was surprising because previous studies had shown that fathers had lower levels of distress (Pace et al., 2016).

Trauma is defined as distressing or disturbing events experienced by individuals or their loved ones that hurt or damage their physical and mental wellbeing in various ways (Ozturk \& Ulusahin, 2016). Although an individual may not experience it firsthand, witnessing such a damaging event can also be traumatic. Traumatic events are of a dangerous or damaging nature; they occur suddenly and lead to fear, anxiety, withdrawal, and avoidance (Turksoy, 2003). When experiencing trauma or an unwanted change, individuals can present three types of psychological reactions, which are as follows: post-traumatic stress disorder (PTSD), resilience/recovery, and post-traumatic growth (PTG; Hefferon \& Boniwell, 2011).
Trauma's impact on mental health is not always negative. In his book titled Man's Search for Meaning, Viktor E. Frankl (1946/2006) - the founder of logotherapy - stated that people can change their attitude towards their faith if they find meaning in their suffering. According to Frankl, people begin changing to convert a personal tragedy into growth only when the situation becomes inevitable. Individuals can experience a positive transformation following a traumatic experience. PTG is described as improvements that occur after highly stressful life crises (Calhoun \& Tedeschi, 1999). It usually manifests in changed priorities in life, perceiving life to be more valuable, realizing one's own power, establishing more intimate relationships, gaining awareness of personal strength, and developing a better understanding of spiritual matters. Hospitalization of an infant in neonatal intensive care involving the risk of death is a traumatic experience for that infant's parents (Affleck \& Tennen, 1991). A considerable portion of these parents experience acute stress disorder and/ or PTSD (Barr, 2010). However, some parents report surviving the challenge of having an infant in the NICU and emerging from the experience even stronger. Büchi et al. (2007) studied PTG and grief among parents who have lost their premature baby, and mothers were found to experience more intense grief and PTG than fathers did. It was also found that the psychological resilience of the mothers who had children in the NICU related to their growth in this process, and various suggestions were presented to increase this growth (Lee \& Kang, 2020).

Bringing the baby into the family system affects the family atmosphere and the couple's relationship dynamics. If one or both parents perceive the baby as an emotionally and behaviorally difficult baby who is difficult to calm down, the stress of parenting increases. This has a negative impact on the parents' relationship quality (Berryhill et al., 2015).

Researchers suggest that babies growing up in families involving incompatible and angry marital interactions will have difficulty organizing their emotions in stressful situations (Berryhill et al., 2015). Continuous highly emotional stimulation leads to a disorganized relationship between the baby and parents and an inability to self-regulate emotionally on the child's part. A study involving 38 married couples and their 3-month-old babies revealed that the parents, who should be a natural source of relaxation for babies, may paradoxically become triggers of negative emotions, such as fear and anxiety. It is clear that the quality of the relationship between parents is important in terms of ensuring babies' emotional regulation (Owen \& Cox, 1997).

Considering the physical, emotional, social, and financial challenges associated with preterm birth, having a marital relationship with strong dynamics is clearly important for the health of the parents
Premature birth and parent's relationship dynamics 
İlknur Okay, Çiğdem Yavuz Güler and the attention and care they provide to their baby during the NICU stay. It is important for parents to maintain their wellbeing as individuals and as a couple by preserving their relationship satisfaction and emotional connection despite the challenges they face as parents after their baby is discharged from hospital. In this way, parents can provide adequate care to meet premature babies' needs, which are far greater than term babies' needs and include therapies, treatments, and developing a secure attachment in this sensitive period of development.

The aim of this study is to examine the depression, anxiety, stress, and PTG experienced by parents after preterm birth from the perspective of relationship dynamics. To achieve this purpose, the study examines whether depression/anxiety/stress has a mediating role between relationship dynamics and PTG, seeking to answer the following research questions:

1. Do depression, anxiety, and stress after preterm birth play a mediating role between the relationship satisfaction of parents of preterm babies and their PTG levels?

2. Do depression, anxiety, and stress after preterm birth play a mediating role between the emotional dependency of parents of preterm babies and their PTG levels?

\section{PARTICIPANTS AND PROCEDURE}

\section{PARTICIPANTS}

The initial number of participants in the study was 1,828 (Figure 1). Data were collected online using Survey Monkey forms. The inclusion criteria were as follows: being a married mother or father of a preterm infant born at or before 32 gestational weeks, a singleton birth, a baby of not more than 12 months old, and a lack of congenital anomaly in the baby. Our rationale for including the parents of infants born at or before 32 weeks is that they make up the group with the highest risk of long-term health problems (Keller et al., 2011). In addition, in many low-income countries, only $30 \%$ of neonates born at this stage survive, with almost all infants $<28$ weeks dying in the first days of their lives (Blencowe et al., 2012). As illustrated in statistics published by the Turkish Ministry of Health, in 2017, 56.2\% of infants born at $<32$ weeks did not survive (Turkish Ministry of Health, 2017). We think that the parents of the most vulnerable babies are at greater risk due to the mortality and morbidity rates.

The parents who participated in this study were not necessarily couples. They should not have been diagnosed with any mental disorders because the study includes depression, anxiety, and stress as mediating variables between PTG and relationship dynamics - namely, relationship satisfaction and emotional dependency. We think that any mental health disorder may be a confounding factor when responding to the relevant scales. For this study, 209 individuals with preterm babies, including 159 women (76.1\%) and 50 men (23.9\%), were included in the analyses based on the inclusion criteria. The age ranges of the participants were $20-40$ years for women and 24-50 years for men, with a mean age of 31.01 years $(S D=5.35)$. Of the participants, 121 (57.9\%) were employed, whereas 88 (42.1\%) were not. Twenty-one participants (10\%) described their income level as inadequate, $95(45.5 \%)$ as partially adequate, and $93(44.5 \%)$ as adequate. When asked whether they or their spouses had had a miscarriage, 46 participants (22\%) responded yes, and $163(78 \%)$ responded no. The age distribution of infants in the study was as follows: $<1$ month, $n=34$ (16.27\%); $1-3$ months, $n=39$ (18.66\%); 4-6 months, $n=48$ (22.97\%); 7-9 months, $n=51$ (24.40\%); and 10-12 months, $n=37$ (17.70\%). The age distribution was unimodal and slightly skewed to the left.

\section{DATA COLLECTION TOOLS}

Sociodemographic form. The sociodemographic form was developed by the researchers to collect information about the parents of preterm infants. The form included questions about the gender and age of the participants; duration of their marriages; employment status of participants and their spouses; level of income; whether major grief had been experienced in the last year outside the preterm birth, such as in the case of job loss, severe disease, accident, or death of a loved one; whether the participants or their spouse had had a miscarriage; whether they had previously lost a baby; the chronological age of the baby at the time of completing the form; the week of birth of babies; whether babies had any congenital anomalies; whether the participants had another child; whether the participants or spouses had previously given birth to a preterm baby; whether the participants or spouses experienced the threat of preterm birth during pregnancy; whether participants had been diagnosed with a mental disorder; and whether participants considered preterm birth as a traumatic event.

The Relationship Assessment Scale. The Relationship Assessment Scale (RAS) was developed by Hendrick et al. (1998) to measure satisfaction in romantic relationships. The scale was adapted into Turkish by Curun (2001). The seven-item assessment uses a 7-point Likert scale. Factor analysis has revealed one general factor, and the internal consistency coefficient of the scale is .86. A high score on the scale suggests a high relationship satisfaction. The Cronbach's $\alpha$ internal consistency coefficient of the scale was found to be .90 for this study. 


\section{Figure 1}

\section{Participation}

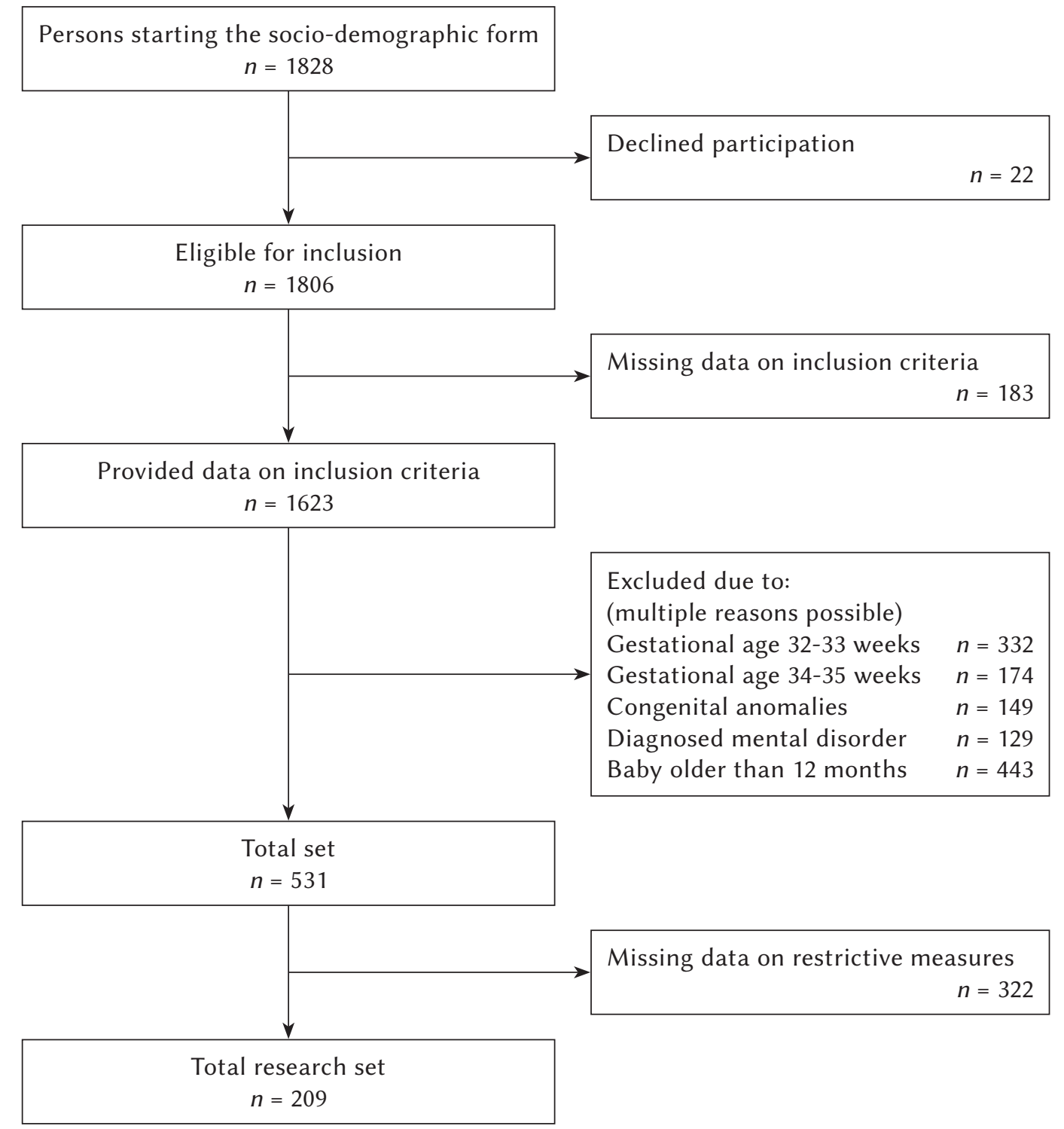

The Emotional Dependency Scale. The Emotional Dependency Scale was developed by Buunk (1981) and adapted to Turkish culture by Karakurt (2001). It measures comparison levels for alternatives, as well as degrees of attachment and interdependency (Buunk, 1995). The nine-item instrument is scored on a 7-point scale. The Cronbach's $\alpha$ value of the original scale was .81 . The Turkish version of the scale has one factor, with a variant of $48.2 \%$. The Cronbach's $\alpha$ internal consistency coefficient of the scale was found to be .92 for this study.

Post-Traumatic Growth Inventory. The PTG Inventory was developed by Tedeschi and Calhoun (1996) to evaluate the changes people experience after a traumatic experience, and it is made up of five factors and 21 items. A high score on the scale suggests that the individual experiences a high level of growth in the relevant factor. The inventory was adapted into Turkish by Duru (2006). The Cronbach's $\alpha$ internal consistency coefficient of the Turkish adaptation of the inventory was .93 , and the total variant of the five-factor structure was $67.84 \%$. The Cronbach's $\alpha$ internal consistency coefficient of the scale was found to be .92 for this study.

The Depression, Anxiety, and Stress Scale. The Depression, Anxiety, and Stress Scale distinguishes anxiety, depression, and stress in terms of the dimension and category. This scale, which was developed by Lovibond and Lovibond (1995) and adapted to Turkish by Bilgel and Bayram (2010), is made up of 42 items and uses a 4-point Likert scale. For the internal consistency of the scale, the Cronbach's $\alpha$
Premature birth and parent's relationship dynamics 
İlknur Okay, Çiğdem Yavuz Güler coefficients were calculated as $.92, .86$, and .88 for depression, anxiety, and stress, respectively. In terms of validity, the root mean square error of approximation (RMSEA) was calculated as .08, goodness of fit index (GFI) as .79, and comparative fit index (CFI) as .75 based on confirmatory factor analysis. The Cronbach's $\alpha$ values for the internal consistency coefficients of the scale were found to be $.86, .89$, and .90 for the factors of depression, anxiety, and stress, respectively, for our study.

\section{DATA COLLECTION AND ANALYSIS}

The study procedures were approved by the Research Ethics Board of Uskudar University, no. 61351342/2019-313 dated 31.05.2019. The data were collected between March 2019 and February 2020, before the COVID-19 pandemic.

The study design is correlational and aims to determine the presence and/or degree of change between two or more variables (Karasar, 2012). Structural equation model analysis was used to analyze the data. Before evaluating the intervention models, the correlations between the variables were analyzed using the Pearson correlation coefficient. Then, the mediation models were tested in line with the research questions. These models were analyzed using the regression-based bootstrapping technique via the PROCESS macro developed by Hayes (2018). With general use, models were developed to perform 5,000 bootstraps, and bootstrapping coefficients and confidence intervals were created. To ensure the significance of results, the upper and lower limits of the confidence intervals were analyzed, and it was concluded that the analysis was significant when these limits did not cover zero (Preacher \& Hayes, 2008).

\section{RESULTS}

\section{FINDINGS ON DIFFERENCES BETWEEN MOTHERS AND FATHERS BY VARIABLE}

An independent-sample $t$-test was performed to determine whether the variables involved in the study differed significantly by gender. Related findings are presented in Table 1.

Table 1 shows the mean values and SDs based on the scores of the participating mothers and fathers. According to the findings, relationship satisfaction $(t=0.66, p=.512)$, emotional dependency $(t=1.69$, $p=.093)$, and stress $(t=1.80, p=.073)$ scores of mothers and fathers did not differ significantly. In contrast, there were significant differences in PTG $(t=2.31$, $p=.022)$, depression $(t=2.99, p=.003)$, and anxiety $(t=2.79, p=.006)$. This shows that the levels of PTG, depression, and anxiety of mothers were higher than those of fathers.

\section{RESULTS OF CORRELATIONS BETWEEN VARIABLES}

In the study, which examined depression, anxiety, stress, and PTG experienced by parents with a preterm infant from the perspective of relationship dynamics, the first step was to analyze the correlations

Table 1

Variables in mothers and fathers

\begin{tabular}{|c|c|c|c|c|c|c|c|}
\hline Variable & Parent & $N$ & M & $S D$ & $t$ & $d f$ & $p$ \\
\hline \multirow{2}{*}{ Relationship satisfaction } & Mother & 159 & 38.82 & 8.69 & 0.66 & 207 & .512 \\
\hline & Father & 50 & 39.74 & 8.61 & & & \\
\hline \multirow[t]{2}{*}{ Emotional dependency } & Mother & 159 & 44.12 & 15.07 & 1.69 & 207 & .093 \\
\hline & Father & 50 & 48.16 & 13.73 & & & \\
\hline \multirow[t]{2}{*}{ Post-traumatic growth } & Mother & 159 & 61.24 & 19.20 & 2.31 & 207 & .022 \\
\hline & Father & 50 & 53.88 & 21.03 & & & \\
\hline \multirow[t]{2}{*}{ Depression } & Mother & 159 & 13.18 & 7.99 & 2.99 & 207 & .003 \\
\hline & Father & 50 & 9.44 & 6.66 & & & \\
\hline \multirow[t]{2}{*}{ Anxiety } & Mother & 159 & 10.43 & 5.97 & 2.79 & 207 & .006 \\
\hline & Father & 50 & 7.80 & 5.26 & & & \\
\hline \multirow[t]{2}{*}{ Stress } & Mother & 159 & 15.73 & 6.46 & 1.80 & 207 & .073 \\
\hline & Father & 50 & 13.86 & 6.22 & & & \\
\hline
\end{tabular}


among variables. The Pearson correlation coefficients are presented in Table 2 .

As shown in Table 2, the relationship satisfaction and emotional dependency $(r=.69, p<.001)$ experienced by parents following the birth of a preterm baby had a positive correlation with PTG $(r=.20$, $p=.005)$. In contrast, a negative correlation was found between relationship satisfaction and depression $(r=-.45, p<.001)$, anxiety $(r=-.25, p<.001)$, and stress $(r=-.27, p<.001)$.

A significant positive correlation was found between the emotional dependency and PTG of parents after having a preterm infant $(r=.29, p<.001)$. In contrast, a significant negative correlation was found between emotional dependency and depression $(r=-.33, p<.001)$ and stress $(r=-.16, p=.021)$ of parents. Finally, no significant correlation was found between emotional dependency and anxiety $(r=-.10$, $p=.164)$. Whereas PTG experienced by parents with preterm infants after preterm birth had a negative significant correlation with depression $(r=-.17$, $p=.017)$, it did not have a significant correlation with anxiety $(r=-.04, p=.579)$ or stress $(r=-.08, p=.243)$.

\section{FINDINGS FROM THE MODEL TESTING}

Regression-based bootstrapping analysis was performed to determine whether depression, anxiety, and stress experienced by parents with preterm infants after preterm birth mediated relationship satisfaction and PTG levels. Figure 2 shows the findings of the model developed to test the mediation of depression, anxiety, and stress in the connection between relationship satisfaction and PTG.

Figure 2 primarily shows direct effects. The relationship satisfaction of parents of preterm infants directly, negatively, and significantly predicts depression following preterm birth $(B=-.40, p<.001)$. Similarly, relationship satisfaction directly, negative-

\section{Table 2}

Correlations with variables

\begin{tabular}{|c|c|c|c|c|c|}
\hline Variable & 1 & 2 & 3 & 4 & 5 \\
\hline 1. Relationship satisfaction & - & & & & \\
\hline 2. Emotional dependency & $.69^{* *}$ & - & & & \\
\hline 3. Post-traumatic growth & $.20^{* *}$ & $.29^{* *}$ & - & & \\
\hline 4. Depression & $-.45^{* *}$ & $-.33^{* *}$ & $-.17^{*}$ & - & \\
\hline 5. Anxiety & $-.25^{* *}$ & -.10 & .04 & $.75^{* *}$ & - \\
\hline 6. Stress & $-.27^{* *}$ & $-.16^{*}$ & -.08 & $.75^{* *}$ & $.74^{* *}$ \\
\hline
\end{tabular}

Note. ${ }^{*} p<.05,{ }^{* *} p<.01$.

\section{Figure 2}

Mediation of post-preterm birth depression, anxiety, and stress between the relationship satisfaction and post-traumatic growth of parents of preterm infants

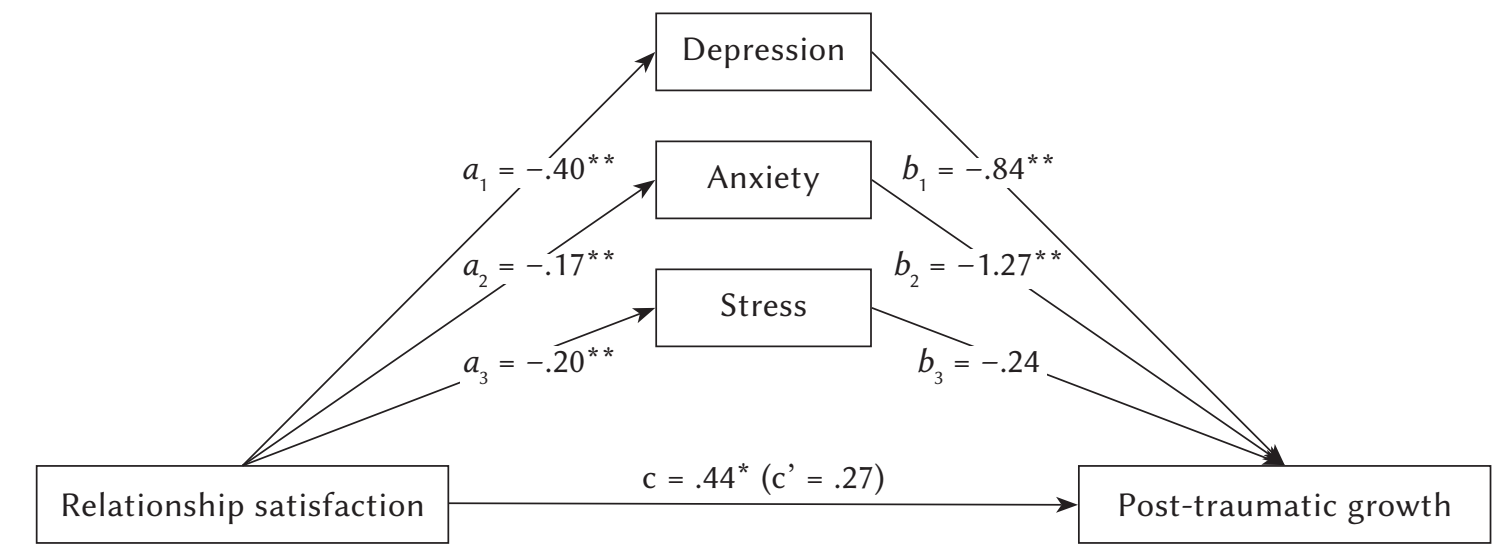

Note. ${ }^{* *} p<.001$, non-standardized coefficients 
İlknur Okay, Çiğdem Yavuz Güler ly, and significantly predicts both anxiety $(B=-.17$, $p<.001)$ and stress $(B=-.20, p<.001)$ following preterm birth. In addition, it was found that depression $(B=-.84, p<.001)$ and anxiety $(B=-1.27, p<.001)$ following a preterm birth directly and negatively predict PTG, while stress $(B=-.24, p=.280)$ does not directly predict PTG.

The total effect of the relationship satisfaction of parents of preterm infants on PTG was found to be .44 and significant. However, with the addition of the mediating variables of depression, anxiety, and stress into the model, this effect dropped to .27, which is insignificant. In this respect, there was full mediation. The bootstrapping coefficient and 95\% confidence intervals (CIs) of the mediation and significance of the effects of the model shown in Figure 2 are presented in Table 3.

As revealed by Table 3, the model developed for PTG was found to be significant $[F(4,204)=5.65$ $p<.001]$. Mediators in the models showed that postpreterm birth depression has a full mediating role between the relationship satisfaction of the par- ents of preterm infants and PTG (bootstrap coefficient $=.35,95 \%$ CI $[.11, .64])$. Similarly, it was found that post-preterm birth anxiety has a full mediating role between the relationship satisfaction of the parents of preterm infants and PTG (bootstrap coefficient $=-.22,95 \% \mathrm{CI}[-.38,-.08])$. In contrast, it was found that post-preterm birth stress does not have a significant mediating role between the relationship satisfaction of the parents of preterm infants and PTG (bootstrap coefficient $=.05,95 \%$ CI $[-.09, .19]$ ).

Regression-based bootstrapping analysis was performed to determine whether depression, anxiety, and stress experienced by parents with preterm infants after preterm birth mediated emotional dependency and PTG levels. Figure 3 shows the findings of the model developed to test the mediation of depression, anxiety, and stress in the connection between emotional dependency and PTG.

Figure 3 primarily shows direct effects. Emotional dependency of parents of preterm infants directly, negatively, and significantly predicts depression following preterm birth $(B=-.17, p<.001)$. Similarly,

Table 3

Bootstrapping results for the mediation of depression, anxiety and stress between relationship satisfaction and post-traumatic growth

\begin{tabular}{lcccccc}
\hline Indirect effect & $\begin{array}{c}\text { Bootstrap } \\
\text { coeficient }\end{array}$ & SE & \multicolumn{2}{c}{$95 \% \mathrm{Cl}$} & \multirow{2}{*}{$R^{2}$} & \multirow{2}{*}{$F(4,204)$} \\
\cline { 4 - 5 } & & & Lower limit & Upper limit & & \\
$\mathrm{RS} \rightarrow$ Depression $\rightarrow$ PTG & .35 & .14 & .11 & .64 & .10 & $5.65^{* *}$ \\
$\mathrm{RS} \rightarrow$ Anxiety $\rightarrow$ PTG & -.22 & .07 & -.38 & -.08 & \\
$\mathrm{RS} \rightarrow$ Stress $\rightarrow$ PTG & .05 & .07 & -.09 & .19 & \\
\hline
\end{tabular}

Note. ${ }^{* *} p<.001 ; \mathrm{RS}$ - relationship satisfaction; PTG - post-traumatic growth.

\section{Figure 3}

Mediation of post-preterm birth depression, anxiety, and stress between the emotional dependency and post-traumatic growth of parents of preterm infants

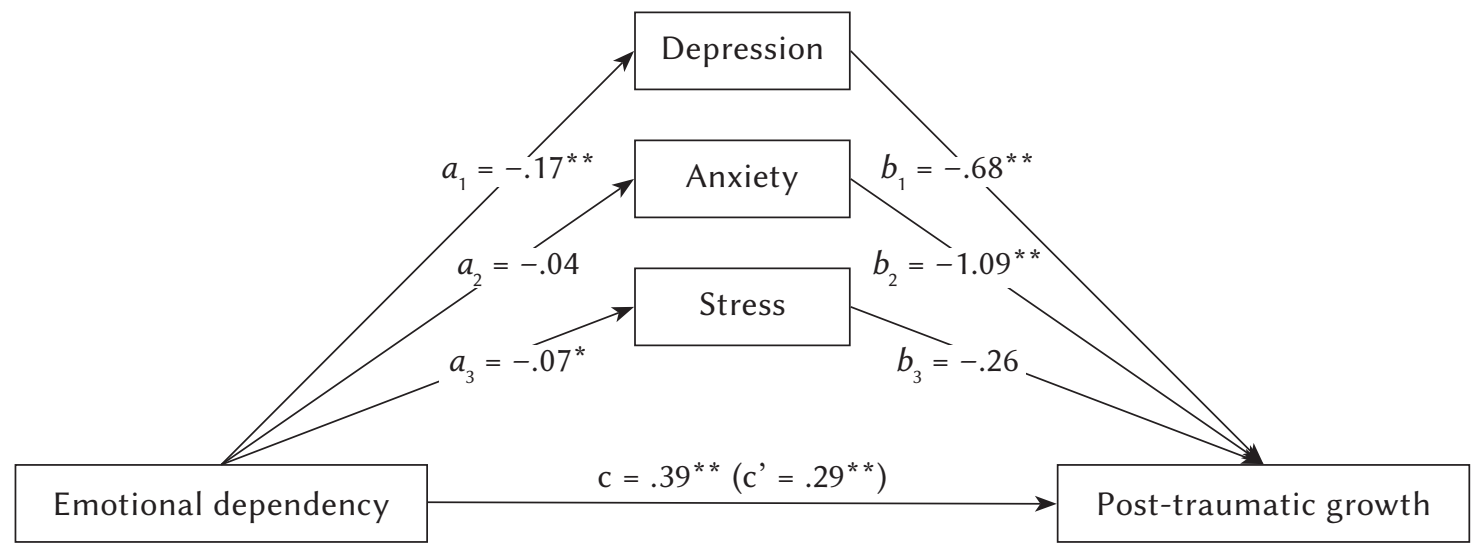

Note. ${ }^{*} p<.05,{ }^{* *} p<.001$, non-standardized coefficients 
Bootstrapping results for the mediation of depression, anxiety, and stress between emotional attachment and post-traumatic growth

\begin{tabular}{|c|c|c|c|c|c|c|}
\hline \multirow[t]{2}{*}{ Indirect effect } & \multirow{2}{*}{$\begin{array}{l}\text { Bootstrap } \\
\text { coefficient }\end{array}$} & \multirow[t]{2}{*}{ SE } & \multicolumn{2}{|c|}{$95 \% \mathrm{Cl}$} & \multirow[t]{2}{*}{$R^{2}$} & \multirow[t]{2}{*}{$F(4,204)$} \\
\hline & & & Lower limit & Upper limit & & \\
\hline ED $\rightarrow$ Depression $\rightarrow$ PTG & .12 & .06 & .02 & .24 & .12 & $7.57^{* *}$ \\
\hline $\mathrm{ED} \rightarrow$ Anxiety $\rightarrow$ PTG & -.04 & .03 & -.10 & .02 & & \\
\hline $\mathrm{ED} \rightarrow$ Stress $\rightarrow$ PTG & .02 & .03 & -.03 & .08 & & \\
\hline
\end{tabular}

Note. ${ }^{* *} p<.001 ; \mathrm{RS}-$ relationship satisfaction; PTG - post-traumatic growth.

Premature birth and parent's relationship dynamics emotional dependency also directly, negatively, and significantly predicts stress $(B=-.07, p=.044)$ following preterm birth. In contrast, emotional dependency does not significantly predict anxiety $(B=-.04$, $p=.445)$.

The total effect of the emotional dependency of preterm infants' parents on PTG was found to be .39 and significant. However, with the addition of the mediating variables of depression, anxiety, and stress into the model, this effect dropped to .29, which is also significant. In this respect, partial mediation was observed. The bootstrapping coefficient and 95\% confidence intervals of the mediation and significance of the effects of the model shown in Figure 3 are presented in Table 4.

As revealed by Table 4, the model developed for PTG was found to be significant $[F(4,204)=7.52$, $p<.001]$. Mediators in the models showed that postpreterm birth depression has a partial mediating role between the emotional dependency of preterm infants and PTG (bootstrap coefficient $=.12,95 \% \mathrm{CI}$ $[.02, .24])$. In contrast, it was found that post-preterm birth anxiety (bootstrap coefficient $=-.04,95 \% \mathrm{CI}$ $[-.10, .02])$ and stress (bootstrap coefficient $=.02$, 95\% CI $[-.03, .08])$ do not have a significant mediating role between the emotional dependency of preterm infants and PTG.

\section{DISCUSSION}

The relationship dynamics of parents are considered decisive and important factors in dealing with the news of preterm birth, labor, lifelong health risks faced by the infant in the NICU, and the challenges brought about by discharge and care at home (Behrman \& Butler, 2007; Hodek et al., 2011). Indeed, it is clear that the strength and accessibility of the couple's resources in the relationship are as crucial as their individual resources in determining how challenging the process will be. This study shows that the dynamics of the relationship between parents also affects whether they can overcome the approaching physical, mental, financial, and social challenges associated with having a preterm infant.

\section{RELATIONSHIP SATISFACTION AND POST-TRAUMATIC GROWTH}

The evaluation of the study findings revealed that based on the direct effects, relationship satisfaction of parents following preterm birth can directly predict depression, anxiety, and stress in a negative and significant way. This finding is consistent with research conducted outside of Turkey (Beach et al., 1990; Ionio et al., 2016; Sokolski \& Hendrick, 1999). In Ozturk and Aydin's (2017) study, marital problems are listed among the psychosocial risk factors affecting perinatal depression. Similarly, in the studies by Sokolski and Hendrick (1999) and Beach et al. (1990), it was found that the risk of depression increases when spouses, regarded as the most important resource in terms of social support, are unable to provide each other with the needed support in marriages that are defined as low quality.

In their study of 160 married couples, Sokolski and Hendrick (1999) reported that intrapersonal factors, such as commitment and love; interpersonal factors, such as self-disclosure; and environmental factors, such as stress affect marital satisfaction. A study conducted in Italy (Ionio et al., 2016) showed that fathers assume the roles of understanding and calming mothers and regulating life outside the NICU; in this context, mothers are faced with stressors related to frequent NICU visits, whereas fathers are unable to attend as frequently because of restricted visiting.

In terms of relationship dynamics, it has been revealed that communication skills and mutual support of partners are among the strongest factors (Hazan \& Shaver, 1987; Litzinger \& Gordon, 2005; Sokolski \& Hendrick, 1999). A study examining the factors affecting the bereavement and PTG of women who had miscarriages found that supportive communication by the spouse and emotional disclosure are among the most important factors predicting PTG (Tian 
İlknur Okay, Çiğdem Yavuz Güler
\& Solomon, 2018). Caring about spouses' emotions, encouraging them to express these emotions clearly, listening to their thoughts and emotions without being critical, approving of their feelings, and making eye contact are considered supportive communication practices by a spouse. These supportive engagements allow individuals to make sense of their loss, express it by reframing, and feel worthy again.

In terms of indirect variables, the effect of relationship satisfaction on PTG was found to be 44 . With the addition of the mediating variables of depression, anxiety, and stress, this effect dropped to .27, which is insignificant. The findings indicate that this variable has a full mediating role. It is thought that among preterm infant parents, the full mediating role depression and anxiety play is caused by subjective perceptions of parents, such as the baby's risk of dying and high levels of anxiety about the future and other factors, such as additional diagnoses the baby might have apart from being preterm.

In their study, Schless et al. (1974) found that depressed people perceive themselves to be more vulnerable to family-related problems and view their experiences as more threatening than they really are; moreover, their capacity to adapt to changes is much lower than that among people without depression. It is thought that having a complicated and high-risk pregnancy before preterm birth and how traumatic the birth is perceived to have been affect the development of depression and anxiety along with the intensity of these disorders. These parameters define the full mediating role of depression and anxiety between relationship satisfaction and PTG. This finding reveals that no matter how high the relationship satisfaction of the parents, a mother or father being depressed or having high anxiety prevents PTG.

Although depression and anxiety mediate fully between the parents' relationship satisfaction and PTG, the study found that stress does not play a significant mediating role in this context. This finding contradicts several studies (Lazarus \& Folkman, 1984) that have shown how stress affects individuals' adaptation skills, such as problem solving and somatic health. In his article, Viner (1999) reviewed the literature related to stress, beginning with Selye, and he described stress as a physiological response to stressors that can be mitigated via individuals' coping mechanisms. Numerous studies have defined depression as a psychopathological state and a potentially life-threatening affective disorder (American Psychiatric Association, 2013; Bondy, 2002). Anxiety is also described in the Diagnostic and Statistical Manual of Mental Disorders, 5th edition (DSM-5) of the American Psychiatric Association (2013) as a disorder where individuals find it difficult to control their worry. The high stressor effects of certain experiences noted in Lazarus and Cohen's (1977) study, such as giving birth or the danger of a loved one dying, were not verified from the perspective of the mediation of stress on relationship satisfaction and PTG considered in the present study. A possible explanation of this result is that stress is a challenge that is relatively easy to cope with compared with anxiety and depression.

\section{EMOTIONAL DEPENDENCY AND POST-TRAUMATIC GROWTH}

According to the findings of our study related to emotional dependency and PTG, when direct effects are considered, emotional dependency of the preterm infants' parents negatively and significantly predicts postpartum depression. Similarly, emotional dependency negatively and significantly predicts stress but does not significantly predict anxiety.

When evaluating the direct effects, the main factors of emotional dependency are considered, and it is thought that the positive emotions shared by the parents about their premature babies, such as love, bonding, and affection; shared negative emotions, such as fear, concern, and despair; and the parents seeing each other as the most significant source of support and becoming attachment figures for each other may be the main factors that support the results of this study (Feeney, 2007). In their study, Ozturk and Aydin (2017) found that one of the key psychosocial factors linked to perinatal depression is having marital problems. This suggests that a strong feeling of love, dependency, and intimacy between spouses will reduce such marital problems.

In their study, Schless et al. (1974) reported that individuals who suffered from depression were much more vulnerable to marriage- and family-related stressors. Our findings suggest that parents with high levels of emotional dependency may be less exposed to marital stressors; we predict that this can reduce the risk of depression.

Relationship satisfaction and emotional dependency, which were found to positively predict PTG in parents of preterm infants following preterm birth, are auxiliary factors in helping parents to make a positive and sensible assessment of how grave the situation is after they face the new reality they experience following the trauma of preterm birth. According to Frankl (2006), to turn a personal tragedy into victory, people must change when they face a situation that cannot be changed. In line with the study findings, parents with high levels of emotional dependency can change their view and see things from a more positive perspective. The concept of optimism, which focuses on the outcomes of a traumatic event and the positive outcomes that will emerge with it, is part of PTG; this suggests that parents with harmonious relationships and emotional dependency can be successful in guiding each other's subjective perceptions to a positive and hopeful path. 
The literature on emotional dependency and anxiety-related studies reports that many parents of preterm infants suffer from high levels of anxiety (Bener, 2013; Pace et al., 2016; Zelkowitz et al., 2007). In contrast, Kemer et al. (2016) noted that emotional dependency is a positive and strong predictor of relationship satisfaction. Although the results of our study on relationship satisfaction showed that this satisfaction is a negative predictor of anxiety, the results we obtained for emotional dependency contradict this view. Even if emotional dependency is high, it cannot negatively predict anxiety experienced by parents of a preterm infant.

When we observed the indirect effects, it was found that the addition of depression, anxiety, and stress to the model as mediating variables reduced the total effect to .29 , which is significant. In this respect, partial mediation was observed. In this study, post-preterm birth depression had a partial mediating role between the emotional dependency of preterm infants' parents and PTG, whereas the mediating effect of stress and anxiety was not significant. A meta-analysis showed that the frequency of depression among mothers of preterm infants, especially in the first year after birth, was significantly higher than that in mothers of term infants (Vigod et al., 2010).

In their study, Alexopoulou et al. (2018) reported that depression is triggered when parents disregard their emotional needs and focus only on their baby if the baby has a life-threatening condition or is in poor health. In line with this study's findings, parents who neglect their own emotional needs are unable to achieve the transformation and change in functionality defined by Tedeshi and Calhoun (2004) as PTG.

The indirect effects show that post-preterm birth anxiety and stress do not have a significant mediating role between the emotional dependency of the parents of preterm infants and PTG. That high emotional dependency can be achieved by accepting and responding to the spouse's attachment needs, as noted in the literature, is in line with this study's findings (Feeney, 2007).

Possible adverse effects of anxiety and stress on PTG can be overcome in parents with high emotional dependency via more effective communication between the parents and better adaptation to each other, as shown by Cirhinlioglu et al. (2017). The partial mediating role of depression between emotional dependency and PTG shows that dependency between couples is a more significant variable in PTG than relationship satisfaction is.

In their study, Lasiuk et al. (2013) noted three factors that affect the ability of parents of preterm infants to adapt to the new reality, which are as follows: the couple's individual and collective resources, the quality of the relationship with the NICU team, and the availability of social and functional support. According to Bowen (1978), all members of a family are inter- connected, and each member of the system affects the others. Therefore, relationship dynamics are as detrimental as the individual resources of the spouses in how parents will experience the period following preterm birth. Couples with a functioning family structure will understand each other socially and emotionally, interact with interest and love, and keep moving forward no matter what hardship comes their way.

Throughout their relationship, all couples create common resources in various areas that they and the other party can benefit from. It is easy and fast to access these resources. Our study revealed that the relationship resources of parents of preterm infants, and especially their emotional dependency, help them overcome the stressful birth and postpartum periods and are highly effective in turning the crisis period into a positive development. It is understood that emotional dependency and relationship satisfaction have protective effects on depression, anxiety, and stress, in addition to positively predicting PTG.

\section{CONCLUSION, LIMITATIONS, AND FUTURE DIRECTIONS}

The purpose of this study was to examine the impact of the relationship dynamics of parents with preterm infants on post-preterm birth depression, anxiety, stress, and PTG. The study showed that postpreterm birth depression and anxiety experienced by parents of preterm infants had a full mediating effect between their relationship satisfaction and PTG levels. The study also demonstrated that postpartum depression experienced by parents of preterm infants played a partial mediating role between their emotional dependency and PTG levels.

There are some limitations of this study that need to be acknowledged. First, our study covered accessible parents with preterm infants in Turkey, and the number of fathers reached was quite low compared with the number of mothers. This situation can be considered the most important limitation of the study. It is recommended that the findings of the study be tested in a larger sample, with more fathers participating, and in different cultures. Another limitation is that the educational status of mothers and fathers was not considered as a variable in the study. In subsequent studies, the educational status of the parents can also be considered as a variable. Here, the stress, anxiety, and depression levels of the parents were considered as variables. That the traumatic effects of having a premature baby were not addressed can be seen as a limitation: This study focused on PTG, but subsequent research may focus primarily on measures of parental trauma levels. In addition, the results of the study can be retested according to the infants' characteristics, such as the gestational birth week, future risk factors, and post-discharge developmental and health
Premature birth and parent's relationship dynamics 
İlknur Okay, Çiğdem Yavuz Güler problems. Long-form and self-administered questionnaires are frequently left unfinished (Andreais \& Kartsounidou, 2020), and we observed this phenomenon in our survey. Those who did not complete the survey might have significant value for our study. Finally, conducting an online survey carries the risk of selection bias (Blumenberg \& Barros, 2018), and this might affect the representation of participants who live in rural areas and/or have limited internet access.

In addition to today's medical understanding of how to keep preterm infants alive and discharge them without any sequelae, it is clear that family members also need one another in the sense of psychological support. The study findings revealed the importance of establishing family- and baby-centered neurodevelopmental NICUs. Both parents being present can reduce the strain on their relationship dynamics and allow mothers and fathers to serve as primary caregivers rather than merely visitors; as a result, a twoway bond can form between the parents and the baby.

It is thought that having healthcare professionals, primarily nurses and doctors, make observations about the relationship dynamics of parents during their stay at the NICU and guide them to receive psychological support if they perceive weaknesses in the relationship - since this predicts possible risks with regard to depression, anxiety, and stress - will uphold the functionality of families. The nature of the family dynamic an infant will experience after discharge is pivotal in its effect on the ongoing therapy, treatment, and possible developmental problems that could emerge in the future.

It is important to develop and give early intervention and psychological first aid training to parents before discharge of the infant; this should focus on the biopsychosocial development of preterm infants, who may need responsive parenting and timely, adequate, and constant attention much more than term infants do. Following discharge, in addition to routine checks of infants, it is also important to measure the variables and stress factors of couples' dynamics and guide those with high risk toward psychiatric outpatient services and/or psychotherapy. In future studies, it would be helpful to analyze the effects of the relationship dynamics of parents on the critical developmental processes of preterm infants. In addition, it would be beneficial for the literature and experts working in the field to investigate how the relationship dynamics of preterm infants' parents change in the coming years.

\section{RefERENCES}

Affleck, G., \& Tennen, H. (1991). The effect of newborn intensive care on parents' psychological wellbeing. Children's Health Care, 20, 6-14. https://doi. org/10.1207/s15326888chc2001_2
Alexopoulou, P., Evagelou, E., Mpakoula-Tzoumaka, C., \& Kyritsi-Koukoulari, E. (2018). Assessing anxiety and depression in parents of preterm infants. Journal of Neonatal Nursing, 24, 273-276. https://doi. org/10.1016/j.jnn.2018.05.009

American Psychiatric Association (2013). Desk reference to the diagnostic criteria from DSM-5. APA.

Andreadis, I., \& Kartsounidou, E. (2020). The impact of splitting a long online questionnaire on data quality. Survey Research Methods, 14, 31-42. https://doi. org/10.18148/srm/2020.v14i1.7294

Barlow, D. H. (1988). Anxiety and its disorders. Guilford Publications.

Barr, P. (2010). Acute traumatic stress in neonatal intensive care unit parents: Relation to existential emotion-based personality predispositions. Journal of Loss and Trauma, 15, 106-122. https://doi. org/10.1080/15325020903373128

Beach, S. R. H., Sandeen, E. E., \& O’Leary, D. K. (1990). Depression in marriage: a model for etiology and treatment (treatment manuals for practitioners). Guilford Press.

Behrman, R. E., \& Butler, A. S. (Eds.) (2007). Neurodevelopmental, health, and family outcomes for infants born preterm. National Academies Press.

Bener, A. (2013). Psychological distress among postpartum mothers of preterm infants and associated factors: a neglected public health problem. $R e$ vista Brasileira de Psiquiatria, 35, 231-236. https:// doi.org/10.1590/1516-4446-2012-0821

Berryhill, M. B., Soloski, K. L., Durtschi, J. A., \& Adams, R. R. (2015). Family process: Early child emotionality, parenting stress, and couple relationship quality. Personal Relationships, 23, 23-41. https:// doi.org/10.1111/pere.12109

Bilgel, N., \& Bayram, N. (2010). Depresyon Anksiyete Stres Ölçeğinin (DASS-42) Türkçe'ye uyarlanmış şeklinin psikometrik özellikleri [Turkish version of the Depression Anxiety Stress Scale (DASS- 42): Psychometric properties]. Nöropsikiyatri Arşivi, 47, 118-126. https://doi.org/10.4274/npa.5344

Blencowe, H., Cousens, S., Chou, D., Ostergaard, M. Z., Say, L., Moller, A. B., Kinney, M., \& Lawn, J. (2012). 15 million preterm births: Priorities for action based on national, regional and global estimates. In C. P. Howson, M. V. Kinney, \& J. E. Lawn (Eds.), Born too soon: The global action report on preterm birth (pp. 17-31). WHO.

Blumenberg, C., \& Barros, A. J. D. (2018). Response rate differences between web and alternative data collection methods for public health research: a systematic review of the literature. International Journal of Public Health, 63, 765-773. https://doi. org/10.1007/s00038-018-1108-4

Bondy, B. (2002). Pathophysiology of depression and mechanisms of treatment. Pathophysiology of Depression, 4, 7-20. https://doi.org/10.31887/dcns. 2002.4.1/bbondy 
Bowen, M. (1978). Family therapy in clinical practice. Aronson.

Butcher, J. N., Mineka, S., \& Hooley, J. M. (2013). Anormal psikoloji [Abnormal psychology]. Kaknus Yayinlari.

Buunk, B. (1981). Jealousy in sexually open marriages. Alternative Lifestyles, 4, 357-372. https://doi. org/10.1007/bf01257944

Buunk, B. (1982). Anticipated sexual jealousy. Personality and Social Psychology Bulletin, 8, 310-316. https://doi.org/10.1177/0146167282082019

Buunk, B. P. (1995). Sex, self-esteem, dependency and extradyadic sexual experience as related to jealousy responses. Journal of Social and Personal Relationships, 12, 147-153. https://doi.org/ 10.1177/0265407595121011

Büchi, S., Mörgeli, H., Schnyder, U., Jenewein, J., Hepp, U., Jina, E., Neuhaus, R., Fauchère, J. C., Bucher, H. U., \& Sensky, T. (2007). Grief and posttraumatic growth in parents 2-6 years after the death of their extremely premature baby. Psychotherapy and Psychosomatics, 76, 106-114. https:// doi.org/10.1159/000097969

Calhoun, L. G., \& Tedeschi, R. G. (1999). Facilitating posttraumatic growth: a clinician's guide. Routledge.

Cirhinlioglu, F. G., Tepe, Y. K., \& Cirhinlioglu, Z. (2017). Psychological distress, self esteem and emotional dependency of married individuals as predictors of marital adjustment. Procedia Computer Science, 120, 164-171. https://doi.org/ 10.1016/j.procs.2017.11.224

Curun, F. (2001). The effects of sexism and sex role orientation on romantic relationship satisfaction [Master's thesis]. Middle East Technical University.

Davis, L., Edwards, H., Mohay, H., \& Wollin, J. (2003). The impact of very premature birth on the psychological health of mothers. Early Human Development, 73, 61-70. https://doi.org/10.1016/s03783782(03)00073-2

Didericksen, K. W., Edwards, A. E., Wetchler, J. L., \& Walker, J. A. (2015). Maternal well-being. The Family Journal, 23, 56-64. https://doi.org/ $10.1177 / 1066480714547186$

Duru, C. (2006). Exploring posttraumatic stress symptoms and posttraumatic growth with respect to some variables and proposing a model [Doctoral dissertation]. Hacettepe University.

Erol, R. Y., \& Orth, U. (2013). Actor and partner effects of self-esteem on relationship satisfaction and the mediating role of secure attachment between the partners. Journal of Research in Personality, 47, 26-35. https://doi.org/10.1016/j.jrp.2012.11.003

Farooqi, S. R. (2014). The construct of relationship quality. Journal of Relationships Research, 5, E2. https://doi.org/10.1017/jrr.2014.2

Feeney, B. C. (2007). The dependency paradox in close relationships: Accepting dependence promotes independence. Journal of Personality and Social Psy- chology, 92, 268-285. https://doi.org/10.1037/00223514.92.2.268

Frankl, V. E. (2006). Man's Search for Meaning. Beacon Press.

Goldberg, S. (1978). Prematurity: Effects on parentinfant interaction. Journal of Pediatric Psychology, 3, 137-144. https://doi.org/10.1093/jpepsy/3.3.137

Hayes, A. F. (2018). Introduction to mediation, moderation, and conditional process analysis: a regressionbased approach (methodology in the social sciences). Guilford Press.

Hazan, C., \& Shaver, P. (1987). Romantic love conceptualized as an attachment process. Journal of Personality and Social Psychology, 52, 511-524. https://doi.org/10.1037/0022-3514.52.3.511

Hefferon, K., \& Boniwell, H. (2011). Positive psychology theory, research and applications. Open University Press.

Hendrick, S. S., Dicke, A., \& Hendrick, C. (1998). The relationship assessment scale. Journal of Social and Personal Relationships, 15, 137-142. https:// doi.org/10.1177/0265407598151009

Hodek, J. M., von der Schulenburg, J. M., \& Mittendorf, T. (2011). Measuring economic consequences of preterm birth - methodological recommendations for the evaluation of personal burden on children and their caregivers. Health Economics Review, 1, 6. https://doi.org/10.1186/2191-1991-1-6

Howson, C. P., Kinney, M. V., McDougall, L., \& Lawn, J. E. (2013). Born too soon: Preterm birth matters. Reproductive Health, 10, 1-9. https://doi. org/10.1186/1742-4755-10-S1-S1

Ionio, C., Colombo, C., Brazzoduro, V., Mascheroni, E., Confalonieri, E., Castoldi, F., \& Lista, G. (2016). Mothers and fathers in NICU: The impact of preterm birth on parental distress. Europe's Journal of Psychology, 12, 604-621. https://doi.org/ 10.5964/ejop.v12i4. 1093

Jotzo, M., \& Poets, C. F. (2005). Helping parents cope with the trauma of premature birth: an evaluation of a trauma-preventive psychological intervention. Pediatrics, 115, 915-919. https://doi.org/10.1542/ peds.2004-0370

Karakurt, G. (2001). The impact of adult attachment styles on romantic jealousy [Master's thesis]. Middle East Technical University.

Karasar, N. (2012). Scientific research methods. Nobel Akademik Yayıncılık.

Keller, M., Saugstad, O. D., Steenbrugge, G., Mader, S., \& Thiele, N. (Eds.) (2011). Caring for tomorrow EFCNI white paper on maternal and newborn health and aftercare services. European Foundation for the Care of Newborn Infants.

Kelley, H. H., \& Thibaut, J. W. (1978). Interpersonal relations: a theory of interdependence. John Wiley $\&$ Sons.

Kemer, G., Cetinkaya-Yildiz, E., \& Bulgan, G. (2016). Emotional dependency and dysfunctional rela-
Premature birth and parent's relationship dynamics 
İlknur Okay, Çiğdem Yavuz Güler tionship beliefs as predictors of married turkish individuals' relationship satisfaction. The Spanish Journal of Psychology, 19, 1-8. https://doi.org/ $10.1017 /$ sjp. 2016.78

Lasiuk, G. C., Comeau, T., \& Newburn-Cook, C. (2013). Unexpected: an interpretive description of parental traumas' associated with preterm birth. BMC Pregnancy and Childbirth, 13, 1-10. https:// doi.org/10.1186/1471-2393-13-s1-s13

Lazarus, R. S., \& Cohen, J. B. (1977). Environmental stress. In I. Altman \& J. F. Wohlwill (Eds.), Human behavior and environment (pp. 89-127). Springer Publishing.

Lazarus, R. S., \& Folkman, S. (1984). Stress, appraisal and coping. Springer Publishing.

Leahy-Warren, P., Coleman, C., Bradley, R., \& Mulcahy, H. (2020). The experiences of mothers with preterm infants within the first-year post discharge from NICU: Social support, attachment and level of depressive symptoms. BMC Pregnancy and Childbirth, 20, 260. https://doi.org/10.1186/ s12884-020-02956-2

Lee, H. S., \& Kang, S. J. (2020). Factors influencing post-traumatic growth in mothers with premature infants admitted to the neonatal intensive care unit. Child Health Nursing Research, 26, 267-276. https://doi.org/10.4094/chnr.2020.26.2.267

Litzinger, S., \& Gordon, K. C. (2005). Exploring relationships among communication, sexual satisfaction, and marital satisfaction. Journal of Sex \& Marital Therapy, 31, 409-424. https://doi.org/ 10.1080/00926230591006719

Lovibond, P. F., \& Lovibond, S. H. (1995). The structure of negative emotional states: Comparison of the depression anxiety stress scales (DASS) with the Beck depression and anxiety inventories. Behaviour Research and Therapy, 33, 335-343. https:// doi.org/10.1016/0005-7967(94)00075-u

Miles, M. S., \& Holditch-Davis, D. (1997). Parenting the prematurely born child: Pathways of influence. Seminars in Perinatology, 21, 254-266. https:// doi.org/10.1016/s0146-0005(97)80067-5

O’Hara, M. W., \& Swain, A. M. (1996). Rates and risk of postpartum depression - a meta-analysis. International Review of Psychiatry, 8, 37-54. https:// doi.org/10.3109/09540269609037816

Okumus, N. (2012). Finansal ve sosyal yük, ailelerin desteği/aile etkisi [Financial and social burden, family support/family impact]. Prematurk Coalition.

Owen, M. T., \& Cox, M. J. (1997). Marital conflict and the development of infant-parent attachment relationships. Journal of Family Psychology, 11, 152164. https://doi.org/10.1037/0893-3200.11.2.152

Ozturk, M. O., \& Ulusahin, N. A. (2016). Ruh sağlığı ve bozuklukları [Mental health and disorders]. Nobel Tip Kitabevleri.

Ozturk, N., \& Aydin, N. (2017). Anne ruh sağlığının önemi [Importance of maternal mental health].
Marmara Üniversitesi Kadın ve Toplumsal Cinsiyet Araştırmaları Dergisi, 1, 29-36. https://doi.org/ 10.26695/mukatcad.2018.9

Pace, C. C., Spittle, A. J., Molesworth, C. M. L., Lee, K. J., Northam, E. A., Cheong, J. L. Y., Davis, P. G., Doyle, L. W., Treyvaud, K., \& Anderson, P. J. (2016). Evolution of depression and anxiety symptoms in parents of very preterm infants during the newborn period. JAMA Pediatrics, 170, 863-870. https:// doi.org/10.1001/jamapediatrics.2016.0810

Preacher, K. J., \& Hayes, A. F. (2008). Asymptotic and resampling strategies for assessing and comparing indirect effects in multiple mediator models. Behavior Research Methods, 40, 879-891. https://doi. org/10.3758/brm.40.3.879

Robinson, K. J., \& Cameron, J. J. (2012). Self-esteem is a shared relationship resource: Additive effects of dating partners' self-esteem levels predict relationship quality. Journal of Research in Personality, 46, 227-230. https://doi.org/10.1016/j.jrp.2011.12.002

Robinson, L. C., \& Blanton, P. W. (1993). Marital strengths in enduring marriages. Family Relations, 42, 38-45. https://doi.org/10.2307/584919

Rusbult, C. E., \& Buunk, B. P. (1993). Commitment processes in close relationships: an interdependence analysis. Journal of Social and Personal Relationships, 10, 175-204. https://doi.org/ 10.1177/026540759301000202

Rusbult, C. E., \& Verette, J. (1991). An interdependence analysis of accommodation processes in close relationships. Representative Research in Social Psychology, 19, 3-33.

Rusbult, C. E., Verette, J., Whitney, G. A., Slovik, L. F., \& Lipkus, I. (1991). Accommodation processes in close relationships: Theory and preliminary empirical evidence. Journal of Personality and Social Psychology, 60, 53-78. https://doi.org/10.1037/00223514.60.1.53

Schappin, R., Wijnroks, L., Uniken Venema, M. M. A. T., \& Jongmans, M. J. (2013). Rethinking stress in parents of preterm infants: a meta-analysis. PLoS One, 8 , e54992. https://doi.org/10.1371/journal.pone.0054992

Schless, A. P., Schwartz, L., Goetz, C., \& Mendels, J. (1974). How depressives view the significance of life events. British Journal of Psychiatry, 125, 406410. https://doi.org/10.1192/bjp.125.4.406

Shapiro-Mendoza, C. K., Tomashek, K. M., Kotelchuck, M., Barfield, W., Nannini, A., Weiss, J., \& Declercq, E. (2008). Effect of late-preterm birth and maternal medical conditions on newborn morbidity risk. Pediatrics, 121, e223-e232. https:// doi.org/10.1542/peds.2006-3629

Sokolski, D. M., \& Hendrick, S. S. (1999). Fostering marital satisfaction. Family Theraphy, 26, 39-49.

Turkish Ministry of Health (2017). Statistics: Premature. Retrieved from https://hsgm.saglik.gov.tr/depo/birimler/cocuk_ergen_db/dokumanlar/istatistikler/ premature.pdf 
Tedeschi, R. G., \& Calhoun, L. G. (1996). The posttraumatic growth inventory: Measuring the positive legacy of trauma. Journal of Traumatic Stress, 9, 455-471. https://doi.org/10.1002/jts.2490090305

Tedeschi, R., \& Calhoun, L. (2004). Posttraumatic growth: Conceptual foundations and empirical evidence. Psychological Inquiry, 15, 1-18. https:// doi.org/10.1207/s15327965pli1501_01

Tian, X., \& Solomon, D. H. (2018). Grief and posttraumatic growth following miscarriage: The role of meaning reconstruction and partner supportive communication. Death Studies, 44, 237-247. https://doi.org/10.1080/07481187.2018.1539051

Treyvaud, K., Spittle, A., Anderson, P. J., \& O’Brien, K. (2019). A multilayered approach is needed in the NICU to support parents after the preterm birth of their infant. Early Human Development, 139, 104838. https://doi.org/10.1016/j.earlhumdev.2019.104838

Turksoy, N. (2003). Psikolojik travma ve sonuçları [Psychological trauma and its consequences]. In T. Aker \& M. E. Onder (Eds.), Psikolojik travma ve tanım sorunları [Psychological trauma and definition problems] (pp. 9-21). 5US.

Vigod, S. N., Villegas, L., Dennis, C. L., \& Ross, L. E. (2010). Prevalence and risk factors for postpartum depression among women with preterm and lowbirth-weight infants: a systematic review. BJOG: An International Journal of Obstetrics \& Gynaecology, 117, 540-550. https://doi.org/10.1111/j.14710528.2009.02493.x

Viner, R. (1999). Putting stress in life. Social Studies of Science, 29, 391-410. https://doi.org/10.1177/ 030631299029003003

Zelkowitz, P., Bardin, C., \& Papageorgiou, A. (2007). Anxiety affects the relationship between parents and their very low birth weight infants. Infant Mental Health Journal, 28, 296-313. https://doi.org/ 10.1002/imhj.20137 